\title{
Distantly Metastatic Malignant Neoplasm
}

National Cancer Institute

\section{Source}

National Cancer Institute. Distantly Metastatic Malignant Neoplasm. NCI Thesaurus.

Code C35933.

A malignant tumor that has spread from its original (primary) site of growth to another site distant from the primary site. 